Virginia Commonwealth University vCU Scholars Compass

2017

\title{
Binding mode analyses of NAP derivatives as mu opioid receptor selective ligands through docking studies and molecular dynamics simulation
}

Huiqun Wang

Virginia Commonwealth University

Saheem A. Zaidi

Virginia Commonwealth University

Yan Zhang

Virginia Commonwealth University, yzhang2@vcu.edu

Follow this and additional works at: http://scholarscompass.vcu.edu/chem_pubs

Part of the Chemistry Commons

\section{Downloaded from}

http://scholarscompass.vcu.edu/chem_pubs/73

This Article is brought to you for free and open access by the Dept. of Chemistry at VCU Scholars Compass. It has been accepted for inclusion in Chemistry Publications by an authorized administrator of VCU Scholars Compass. For more information, please contact libcompass@vcu.edu. 


\title{
Binding mode analyses of NAP derivatives as mu opioid receptor selective ligands through docking studies and molecular dynamics simulation
}

\author{
Huiqun Wang ${ }^{\text {a }}$, Saheem A. Zaidi ${ }^{\text {a }}$, Yan Zhang* \\ Department of Medicinal Chemistry, School of Pharmacy, Virginia Commonwealth University, 800 E Leigh Street, Richmond, VA 23298, United States
}

\section{A R T I C L E I N F O}

\section{Article history:}

Received 19 January 2017

Revised 27 February 2017

Accepted 3 March 2017

Available online 6 March 2017

\section{Keywords:}

NAP derivatives

Opioid receptors

Molecular modeling

Dual binding modes

Binding affinity

Selectivity

\begin{abstract}
A B S T R A C T
Mu opioid receptor selective antagonists are highly desirable because of their utility as pharmacological probes for receptor characterization and functional studies. Furthermore, the mu opioid receptors act as an important target in drug abuse and addiction treatment. Previously, we reported NAP as a novel lead compound with high selectivity and affinity towards the mu opioid receptor. Based on NAP, we have synthesized its derivatives and further characterized their binding affinities and selectivity towards the receptor. NMP and NGP were identified as the two most selective MOR ligands among NAP derivatives. In the present study, molecular modeling methods were applied to assess the dual binding modes of NAP derivatives, particularly on NMP and NGP, in three opioid receptors, in order to analyze the effects of structural modifications on the pyridyl ring of NAP on the binding affinity and selectivity. The results indicated that the steric hindrance, electrostatic, and hydrophobic effects caused by the substituents on the pyridyl ring of NAP contributed complimentarily on the binding affinity and selectivity of NAP derivatives to three opioid receptors. Analyses of these contributions provided insights on future design of more potent and selective mu opioid receptor ligands.
\end{abstract}

Published by Elsevier Ltd.

\section{Introduction}

G protein-coupled receptors (GPCRs), one of the largest groups of membrane proteins in the human genome, ${ }^{1}$ play important roles in many physiological processes, such as signal transduction, neurotransmission, immune defense, and cellular metabolism. ${ }^{2,3}$ Opioid receptors belong to the rhodopsin-type family A of GPCRs, which are widely distributed in the central nervous system (CNS). ${ }^{4}$ The opioid receptor family includes four subtypes: $\mu$-opioid receptor (MOR), $\kappa$-opioid receptor (KOR), $\delta$-opioid receptor (DOR) and nociceptin receptor (NOP). ${ }^{5-7}$ Among these four receptors, MOR, KOR, and DOR share fairly high amino acid sequence similarity among them. Their crystal structures have been reported recently, ${ }^{8-14}$ which allow us to study their structural characteristics at the atomic level. Moreover, MOR, KOR, and DOR are also involved in many common physiological processes, such as pain perception, depression, anxiety, and drug abuse and addiction. ${ }^{15-}$ ${ }^{18}$ It has been demonstrated that the MOR plays primary role in controlling antinociception, and the DOR is linked to mood related

\footnotetext{
* Corresponding author.

E-mail address: yzhang2@vcu.edu (Y. Zhang).

a These authors contributed equally to this work.
}

disorders, ${ }^{19,20}$ while the KOR is known to cause dysphoric effects as well as anxiety. ${ }^{21-23}$ The demonstration of structural features and physiological symptoms of three opioid receptors make them become promising drug targets for treatment of pain, depression, and drug abuse and addiction. ${ }^{24}$

MOR agonists have been pharmaceutically favored ligands owing to MOR's primary role in pain management system. Traditionally, agonist mediated opioid function can be characterized as such only when their effects are competitively reversed by MOR antagonists. ${ }^{16,25}$ Thus, development of MOR selective antagonists has also become imperative in opioid research. More specially, non-peptidyl, selective, and potent MOR antagonists are highly desired for functional characterization of MOR. ${ }^{26-28}$ Apart from being a pharmacological tool, MOR antagonists may also play a critical role in treatment of substance abuse and addiction. ${ }^{16,18}$ Some partially selective MOR antagonists including naloxone, naltrexone and nalmefene have been reported to have beneficial effects including decrease in drug craving and relapse for opiate addicts as well as in treatment of alcoholism. ${ }^{29-32}$ Although these MOR antagonists are promising, some serious side effects have also been observed. Besides causing depression and dysphoria, ${ }^{26-28,33-35}$ these drugs have also been reported to cause higher incidence of overdoses and suicides among the opiate addict patients ${ }^{29,31,32,36}$ 
due to their affinity to the DOR and KOR and low selectivity to the MOR. Hence, it is plausible that such side effects could be mitigated by development of more selective MOR antagonists.

Previously, we reported a series of naltrexone-derived ligands of opioid receptors. Experimental characterizations, both in vitro and in vivo, of these compounds led us to a particularly potent and selective compound NAP (Fig. 1a), our first generation MOR antagonist. Radioligand binding assays of NAP suggested that it had high binding affinity and selectivity towards the MOR when compared to the $\mathrm{KOR}$ and DOR (MOR $\mathrm{K}_{\mathrm{i}} \approx 0.37 \mathrm{nM}, \mathrm{MOR} /$ $\mathrm{KOR} \approx 164, \mathrm{MOR} / \mathrm{DOR} \approx 750) .{ }^{37}$ Besides, we also reported characterization of molecular interactions involved in binding of NAP in the MOR, KOR, and DOR models derived from their respective Xray crystal structures through molecular modeling studies. These molecular modeling results indicated that the morphinan moiety of NAP located in the 'message' interacting region of the receptors while the heterocyclic pyridyl ring of NAP interacted with either of the two 'address' domains of the receptors. The amino acid residues of the latter domain were non-conserved among the opioid receptors, which conferred its selectivity for the MOR over the KOR and DOR. ${ }^{38}$

Based on the structure of lead compound NAP and its binding modes in the MOR, KOR, and DOR, our second generation MOR antagonists were designed, synthesized, and characterized. ${ }^{39}$ Among these NAP derivatives, NMP and NGP (Fig. 1b and c) were identified as the two most selective MOR antagonists, which showed comparable binding affinity, selectivity, and efficacy to NAP. In this paper, docking studies and molecular dynamics simu- lations were applied to characterize the binding modes of NMP and NGP with three opioid receptors in order to understand how change of substituent properties or their position in the pyridyl ring would lead to similar ligand binding affinity and selectivity. These computational studies coupled with experimental data may give further insights on 'address' domain of opioid receptors and provide valuable information for developing more potent and selective MOR antagonists.

\section{Results and discussion}

\subsection{Analysis of the 'address' moiety of NAP derivatives}

The binding affinity and selectivity of NAP, NMP, and NGP to the MOR, KOR, and DOR together with the pKa values of nitrogen atom on their pyridyl rings in each compound were summarized in Table 1 . The pKa values were estimated by software ACD/I-lab 2.0 (Advanced Chemistry Development, Inc.). It is well-known that pKa value can be used to measure the capability of a molecule or ion to keep a proton $\left(\mathrm{H}^{+}\right)$at its ionization center. The greater the pKa value, the stronger the ability to keep a proton, or, conversely, the lower the value, the weaker to keep a proton. ${ }^{40}$ As the pKa of pyridine is about $5.25,{ }^{41}$ the pyridine would be mainly in unionized form at the physiological $\mathrm{pH}$. However, substitutions on the pyridine ring can change the capability of nitrogen atom on pyridine to keep a proton. That is, an electron donating substitution on pyridyl ring would strengthen such ability, while an electron withdrawing group on pyridyl ring would weaken it. In NAP, the
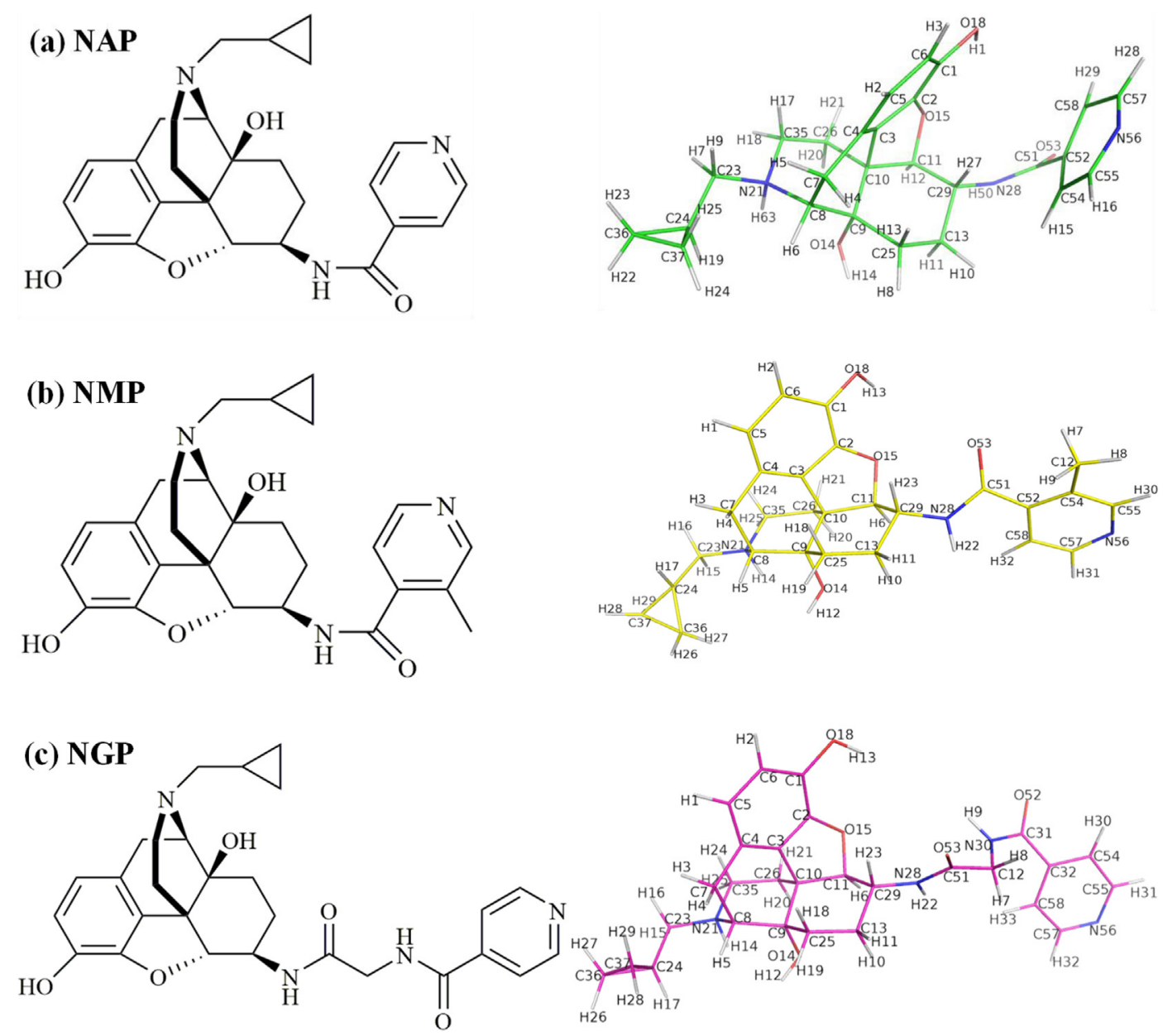

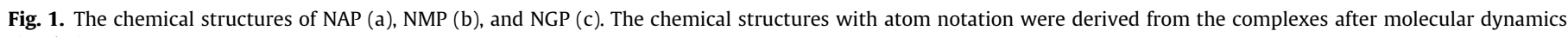
simulations. 
Table 1

The binding affinity and selectivity of NAP, NMP, and NGP together with the pKa value of nitrogen atom on pyridyl ring in each compound.

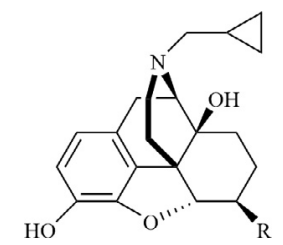

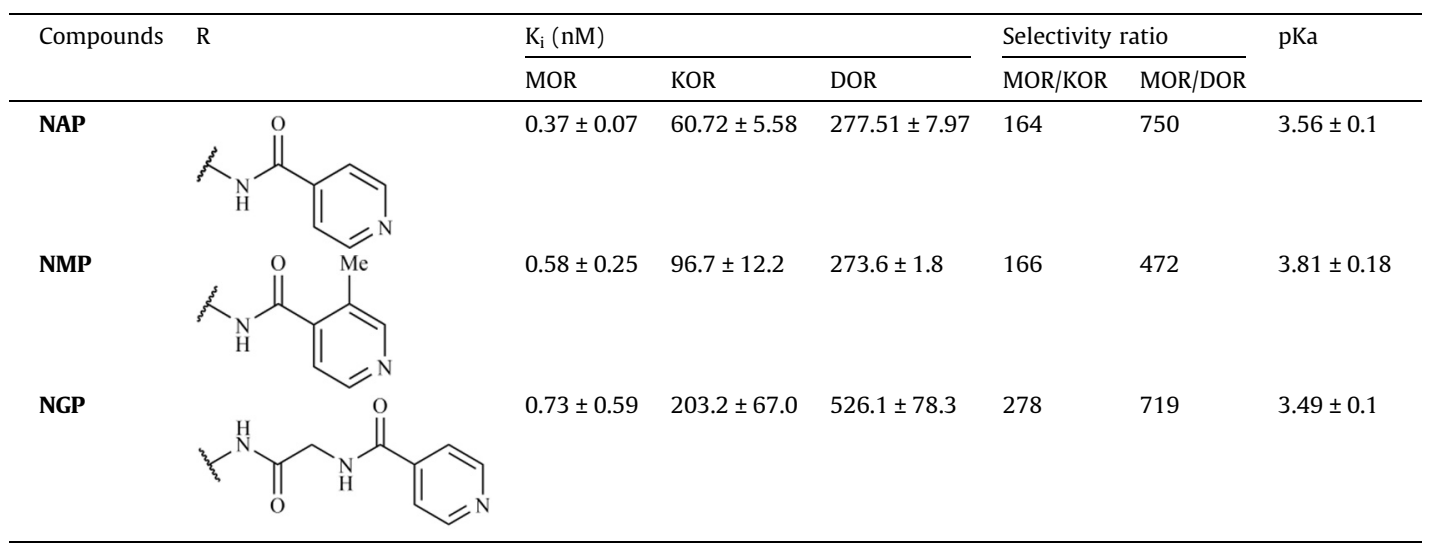

amide linker group was an electron withdrawing group to the pyridyl ring, which would weaken the capability of nitrogen atom on pyridyl ring to keep a proton. Hence, NAP was more likely to stay predominantly in its unionized form at the physiological $\mathrm{pH}$.

As discussed in our previous studies, the amide linker would provide the pyridyl ring of NAP enough flexibility to interact with either of the two 'address' domains of the three opioid receptors. ${ }^{38}$ We defined these two interaction regions as site $A$ and site $B$ (Table 2). Site A included a positively charged residue Lys $303^{6.58}$ and site B had a negatively charged residue Glu229.35 in the MOR. The pyridyl ring of NAP preferred to interact with the site A of the MOR owing to the $\pi-\pi$ stacking interaction between the aromatic pyridyl ring and residue Trp318 7.35 and electrostatic interaction between the electron rich nitrogen atom of pyridyl ring and residue Lys $303^{6.58}$. Since there was no positively charged residues in the KOR and DOR that could interact with electron rich nitrogen atom of pyridyl ring (Table 2), the binding affinities of NAP with KOR and DOR were much lower than that of NAP with the MOR. ${ }^{38,39}$ Therefore, we may conclude that both the aromaticity of the pyridine and the substituent at the pyridyl ring of NAP interacting with the residues in the 'address' domains influenced the binding of NAP to all three opioid receptors.

From Table 1, it could also be observed that both NMP and NGP had comparable binding affinity and selectivity to NAP in all three opioid receptors. Comparing NMP with NAP, there was an extra methyl group on the pyridyl ring of NMP, which could lead to a steric effect in the binding pocket. To NGP, the addition of a glycine group to the amide linker would further increase the length of the space between the 'message' and 'address' moieties. Besides, as the methyl group was an electron donating group to the pyridyl ring of NMP, the capability of the nitrogen atom on the pyridyl ring of NMP to keep a proton would be stronger than that of NAP. While the amide linker group was an electron withdrawing group to the pyridyl ring of NGP, which was the same to that of NAP, consequently, the capability of the nitrogen atom on the pyridyl ring of NGP should be almost equal to that of NAP. The pKa values of nitro- gen atom on pyridyl ring of NAP, NMP, and NGP in Table 1 also confirmed our analyses. In all, besides electrostatic effect, other effects, such as steric and hydrophobic effects caused by the substituent, may influence the binding of NMP and NGP to the receptors. Hence, in order to further understand how these substituents affected the binding modes and affinities of NMP and NGP, docking exercises and molecular dynamics simulations were applied.

\subsection{Docking studies of NMP and NGP}

In our previous studies, NAP was docked into the well-known antagonist binding pockets of the MOR, KOR, and DOR, ${ }^{38}$ which had been proved by various opioid antagonists. ${ }^{37,42-44}$ In the current study, GOLD docking algorism ${ }^{45}$ was again applied to dock both NMP and NGP into the same site of three opioid receptors in the similar fashion to NAP. The optimal docking poses of NMP and NGP in each receptor were chosen based on the highest CHEM-PLP and HINT scores, and these optimal docking results were displayed in Figs. 2 and 3.

It could be seen from Figs. 2 and 3 that the morphinan moiety of NMP and NGP occupied the similar 'message' domain to that of NAP. $^{38}$ That is, the morphinan moiety was housed within a conserved hydrophobic pocket formed by residues $\mathrm{Met}^{3.36}, \operatorname{Trp}^{6.48}$, $\mathrm{His}^{6.52}$, and $\mathrm{Tyr}^{7.43}$ in all three receptors. Typically, piperidine qua-

Table 2

Plausibly critical residues in the 'address' domains along with their dominant chemical feature. $^{38}$

\begin{tabular}{|c|c|c|}
\hline Receptor & Site A & Site B \\
\hline MOR & $\begin{array}{l}\text { Lys } 303^{6.58} \text { and Trp3 } 38^{7.35} \\
\text { Positive and Hydrophobic }\end{array}$ & $\begin{array}{l}\text { Thr2225 } 5.31 \text { and Glu2295.35 } \\
\text { Hydrophobic and Negative }\end{array}$ \\
\hline KOR & $\begin{array}{l}\text { Glu297 } 6.58 \text { and Tyr } 312^{7.35} \\
\text { Negative and Hydrophobic }\end{array}$ & $\begin{array}{l}\text { Tyr } 219^{5.31} \text { and Asp } 223^{5.35} \\
\text { Hydrophobic and Negative }\end{array}$ \\
\hline DOR & $\begin{array}{l}\text { Trp } 284^{6.58} \text { and Leu300 } \\
\text { Hydrophobic }\end{array}$ & $\begin{array}{l}\text { Ser206 } \\
\text { Hydrophobic and Negative }\end{array}$ \\
\hline
\end{tabular}



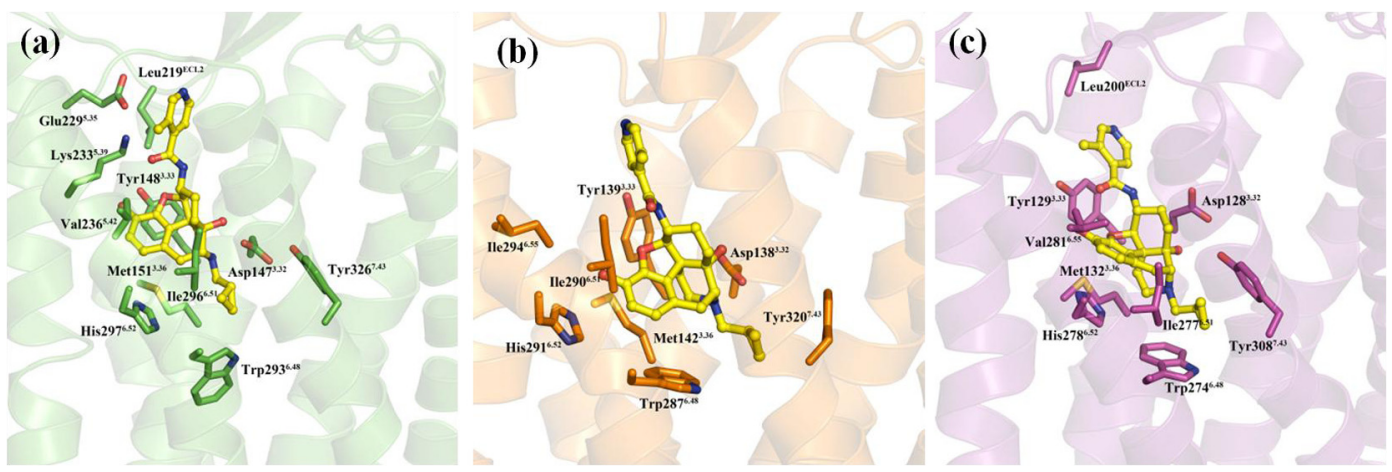

Fig. 2. NMP conformation (yellow balls and sticks) in MOR ${ }^{\text {site } B}$ (a), KOR ${ }^{\text {site B }}$ (b), and DOR site A (c) with highest CHEM-PLP and HINT scores from docking studies.

ternary ammonium nitrogen formed ionic interactions with residue $\mathrm{Asp}^{3.32}$, and the tetrahydrofuran oxygen of the morphinan moiety formed hydrogen bond with residue $\mathrm{Tyr}^{3.33}$. Similar to NAP, due to the flexibility caused by the amide linker, the pyridyl moiety of NMP and NGP may also adopt two different conformations, which could engage two different 'address' domains in each opioid receptor: site A and site B (Table 1). Interestingly, it seemed that from the docking study the pyridyl ring of NMP interacted with site B of MOR and KOR, but occupied site A of DOR while the pyridyl ring of NGP formed interactions with site A of MOR, KOR and site B of DOR (Fig. 3).

\subsection{Molecular dynamics simulations of NMP and NGP within the opioid receptors in a lipid bilayer membrane system}

To further understand the binding modes of NMP and NGP in all three opioid receptors and analyze the interactions between the 'address' interaction region of three opioid receptors and the pyridyl ring of NMP and NGP in more detailed fashion, and more importantly, to provide possible explanation on the difference of docking site preference among NAP, NMP, and NGP, molecular dynamics (MD) simulations were performed on MOR-NMP, KORNMP, DOR-NMP, MOR-NGP, KOR-NGP, and DOR-NGP complexes to optimize these binding modes obtained from the docking studies. For the purpose of obtaining stable systems, 10 ns MD simulations on the six systems in a lipid bilayer membrane system enclosed in a water box were carried out. After that, the rootmean-square deviation (rmsd) values of all the protein backbone atoms based on the respective starting structures were calculated to ensure the stability of all the systems, and the results were displayed (Fig. 4). It seemed that the rmsd values of the backbone atoms in all systems remained stable after 5 ns of MD simulations. And the average rmsd values of MOR-NMP, KOR-NMP, DOR-NMP,
MOR-NGP, KOR-NGP, and DOR-NGP complexes were 1.98, 1.33, $1.72,1.57,1.38$, and $1.56 \AA$, respectively. It has been reported that the rmsd value of a system smaller than $3.0 \AA$ would indicate that the system achieved dynamics equilibrium. ${ }^{46-48}$ Therefore, it can be concluded that the six systems were stabilized after $10 \mathrm{~ns}$ MD simulations.

The binding modes of MOR-NMP, MOR-NGP, KOR-NMP, KORNGP, DOR-NMP, and DOR-NGP complexes after 10 ns MD simulations were displayed in Figs. 5-7 respectively. These figures showed that the 'message' moiety morphinan of NMP and NGP remained in the 'message' domains in the receptors, which was consistent with the docking results. And the 'address' moiety pyridyl ring of NMP and NGP in MOR, KOR, and DOR interacted with the 'address' binding domain, but the binding site was different from the docking results. For example, the pyridyl ring of NMP interacted with site B of the MOR from the docking study while it now resided in site $A$ of the MOR after MD simulation (see detailed analyses in the following sections). The residues located at site A or site B in the MOR, KOR, and DOR were showed in Table 3 . In this table, amino acid residues contributing significantly to binding of the pyridyl ring of NAP, NMP, and NGP were displayed in bold.

\subsection{Analysis of NMP and NGP in the 'address' domain of the MOR after MD simulations}

In the MOR-NMP complex, the methyl group on the pyridyl ring of NMP could strengthen the capability of nitrogen atom on pyridyl ring to keep a proton while two positively charged residues Lys $233^{5.39}$ and Lys $303^{6.58}$ in site A of the MOR were not close enough. The electrostatic expelling force between the pyridyl ring of NMP and residues Lys $233^{5.39}$ and Lys $303^{6.58}$ probably was not strong enough to influence the binding of the pyridyl ring of
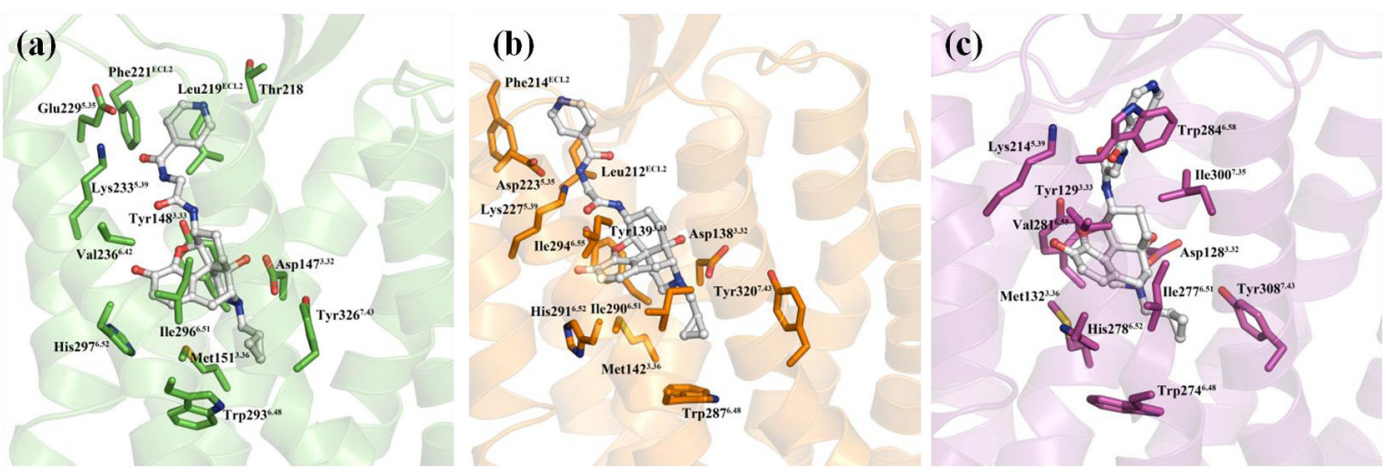

Fig. 3. NGP conformation (white balls and sticks) in MOR ${ }^{\text {siteA }}$ (a), KOR ${ }^{\text {site A }}$ (b), and DOR ${ }^{\text {site } B}$ (c) with highest CHEM-PLP and HINT scores from docking studies. 


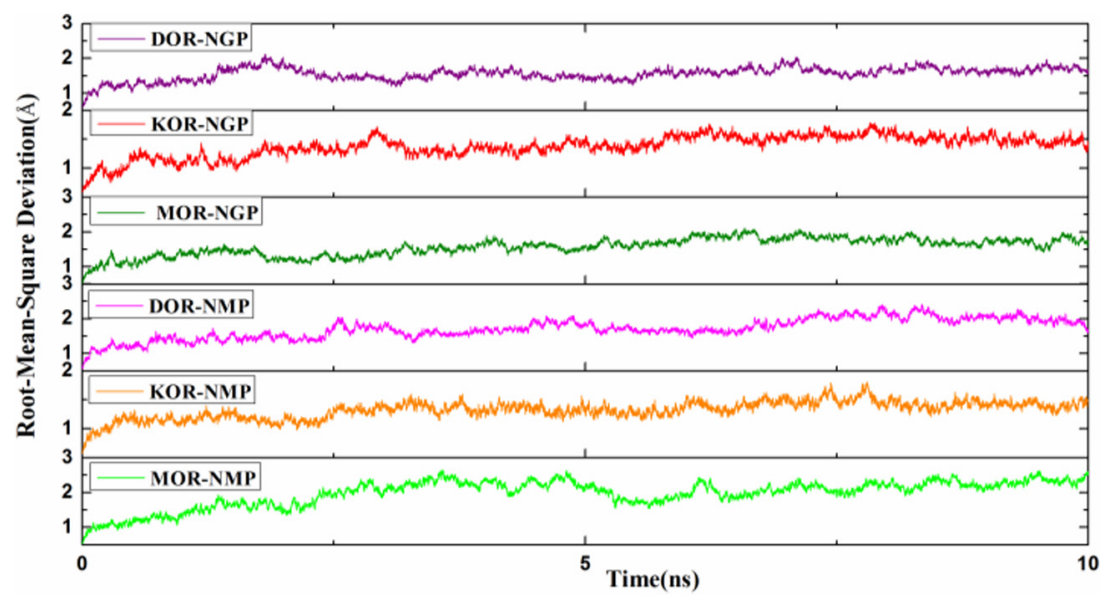

Fig. 4. The root-mean-square-deviation (rmsd) of the protein backbone atoms of the six complexes relative to the respective starting structures.
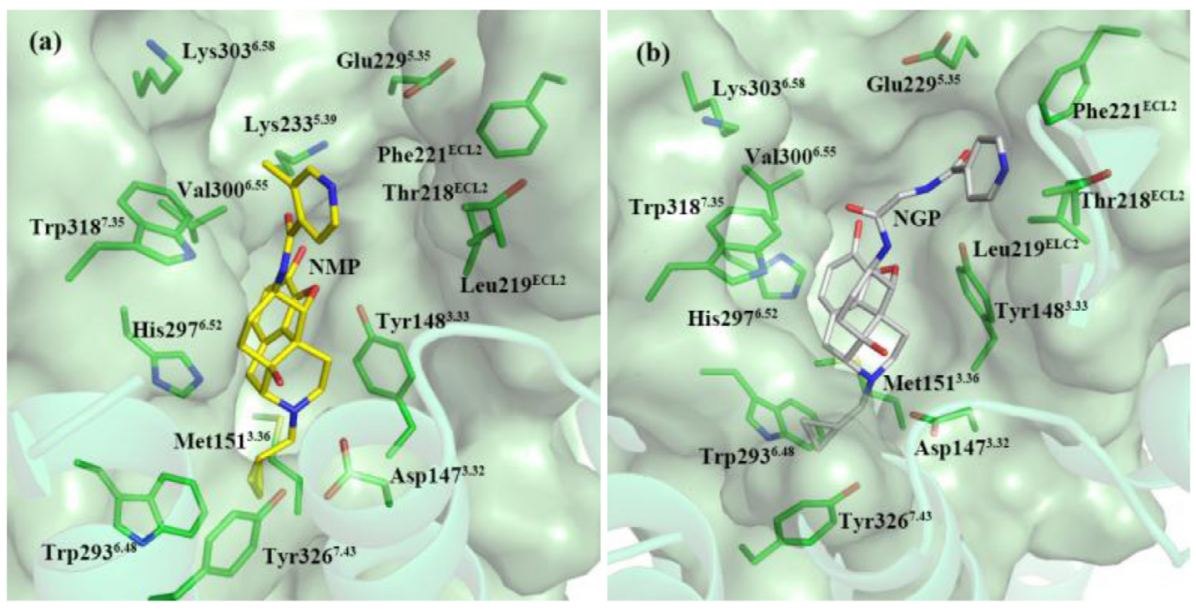

Fig. 5. Binding modes of $M O R^{\text {site }} A_{-}-N M P(a)$ and $M O R^{\text {site }}{ }^{B}-N G P(b)$ complexes with key residues in the binding pocket after 10 ns $M D$ simulations.

(a)

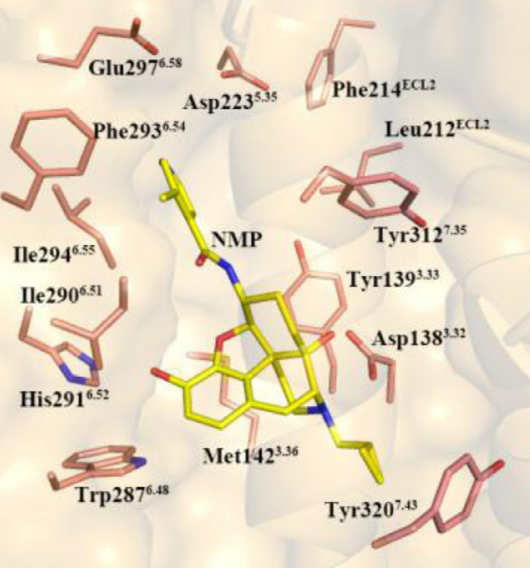

(b)

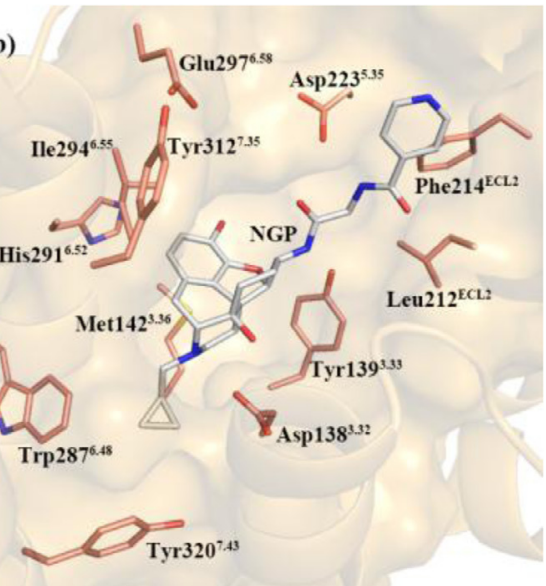

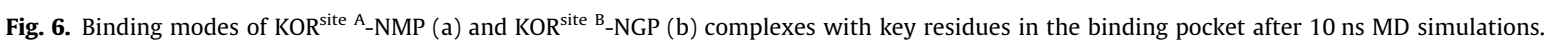

NMP in site A. In consequence, the pyridyl ring of NMP still preferred to interact with $\operatorname{Trp} 318^{7.35}$ in site A of the MOR (Fig. 5a). Meanwhile, this methyl group also could result in steric hindrance effect, leading to the pyridyl ring of NMP moving slightly away from residues Lys $233^{5.39}$, Val300 6.55 , and Lys $303^{6.58}$ (Table 4) compared to that of NAP. Consequently, the electrostatic interactions with residues Lys233 3.39 and Lys $303^{6.58}$ and the hydrophobic interaction with residue Val $300^{6.55}$ from the pyridyl ring of NMP were relatively weaker than those in the MOR-NAP complex. On the other hand, such a movement would lead to the distance decrease between the pyridyl ring of NMP and residue Trp318 ${ }^{7.35}$ which further strengthened the $\pi-\pi$ stacking interaction between the aro- 

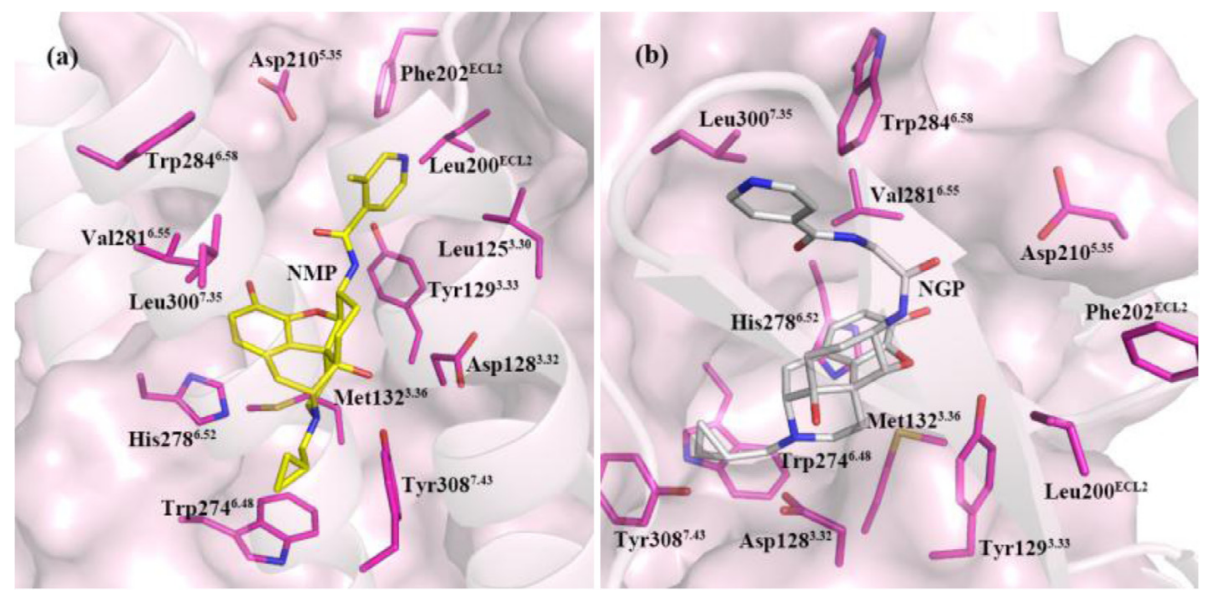

Fig. 7. Binding modes of $\mathrm{DOR}^{\text {site }} \mathrm{B}_{-} \mathrm{NMP}(\mathrm{a})$ and $\mathrm{DOR}^{\text {site }} \mathrm{A}_{-} \mathrm{NGP}(\mathrm{b})$ complexes with key residues in the binding pocket after 10 ns $\mathrm{MD}$ simulations.

Table 3

The residues at site A or site B in MOR, KOR, and DOR. ${ }^{a}$

\begin{tabular}{|c|c|c|c|c|c|c|}
\hline & \multicolumn{2}{|l|}{ MOR } & \multicolumn{2}{|l|}{ KOR } & \multicolumn{2}{|l|}{ DOR } \\
\hline & Site A & Site B & Site A & Site B & Site A & Site B \\
\hline NAP & $\begin{array}{l}\text { Lys233 } \\
\text { Ile296 } \\
\text { His.51 } \\
\text { His297 }^{6.52} \\
\text { Val300 }^{6.55} \\
\text { Lys303 }^{\mathbf{6 . 5 8}} \\
\text { Trp318 } \\
\text { Ile32.35 } \\
\end{array}$ & $\begin{array}{l}\text { Thr218 } \\
\text { Leu219 }^{\text {ECL2 }} \\
\text { Thr220 } \\
\text { ECL2 } \\
\text { Phe221 }^{\text {ECL2 }} \\
\text { Thr225 } \\
\text { Glu1 } \\
\text { Glu2 }^{5.35}\end{array}$ & $\begin{array}{l}\text { Ile290 }^{6.51} \\
\text { His291 } \\
\text { Phe293 } \\
\text { Ile294 } \\
\text { Il.55 } \\
\text { Glu297 }^{6.58} \\
\text { Tyr312 }^{7.35}\end{array}$ & $\begin{array}{l}\text { Ser211 }^{\text {ECL2 }} \\
\text { Leu212 } \\
\text { Phe214 } \\
\text { Tyr219 } \\
\text { 5C.31 } \\
\text { Asp223 }^{\mathbf{5 . 3 5}} \\
\text { Lys227 }^{\mathbf{5 . 3 9}}\end{array}$ & $\begin{array}{l}\text { Val281 }^{6.55} \\
\text { Trp284 }^{6.58} \\
\text { Leu300 }^{7.35} \\
\text { Ile3047.39 }\end{array}$ & $\begin{array}{l}\text { Leu125 } 5^{3.29} \\
\text { Tyr129 } \\
\text { Leu200 } 2.33 \\
\text { Phe202 }^{\text {ECL2 }} \\
\text { Ser206 } \\
\text { Asp210 } \\
\text { Lys214 }^{5.35}\end{array}$ \\
\hline NMP & $\begin{array}{l}\text { Lys233 } \\
\text { Ile296.39 } \\
\text { His297 } \\
\text { Val300 }^{6.52} \\
\text { Lys303 }^{6.55} \\
\text { Trp318 } \\
\text { Ile322.35 } \\
\end{array}$ & $\begin{array}{l}\text { Thr218 } \\
\text { Leu219 } 9^{\text {ECL2 }} \\
\text { Thr220 } \\
\text { Phe22 } 21^{\text {ECL2 }} \\
\text { Thr225 } \\
\text { Glu22 } 29^{5.35}\end{array}$ & $\begin{array}{l}\text { Ile290 }^{6.51} \\
\text { His291 } \\
\text { Phe293 }^{6.52} \\
\text { Ile294 }^{\mathbf{6 . 5 5}} \\
\text { Glu297 }^{\mathbf{6 . 5 8}} \\
\text { Tyr312 }^{7.35}\end{array}$ & $\begin{array}{l}\text { Ser211 } 11^{\text {ECL2 }} \\
\text { Leu212 } \\
\text { Phe214 } \\
\text { Tyr219 } \\
\text { Asp22 } 23^{5.31} \\
\text { Lys227 } \\
5.39\end{array}$ & $\begin{array}{l}\text { Val281 } \\
\text { Trp255 } \\
\text { Leu304 } \\
\text { Ile } 304^{7.39}\end{array}$ & $\begin{array}{l}\text { Leu125 } 5^{3.29} \\
\text { Tyr129 } \\
\text { Leu200 } 200^{\text {ECL2 }} \\
\text { Phe202 } 202^{\text {ECL2 }} \\
\text { Ser206 } \\
\text { Asp211 } 210^{5.35} \\
\text { Lys214 }\end{array}$ \\
\hline NGP & $\begin{array}{l}\text { Ile296 } \\
\text { His297 } \\
\text { Val30.52 } \\
\text { Lys.55 } \\
\text { Lys303 } \\
\text { Trp318 } 318^{7.35} \\
\text { Ile3222.39 }\end{array}$ & $\begin{array}{l}\text { Thr218 } \\
\text { Leu219 }^{\text {ECL2 }} \\
\text { Thr220 } \\
\text { ECL2 } \\
\text { Phe221 }^{\text {ECL2 }} \\
\text { Thr225 } \\
\text { Glu1 } 229^{5.35}\end{array}$ & 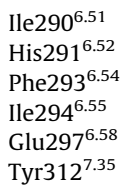 & $\begin{array}{l}\text { Ser211 } \\
\text { Leu212 }^{\text {ECL2 }} \\
\text { Phe214 }^{\text {ECL2 }} \\
\text { Tyr219 } \\
\text { Asp2231 } \\
\text { Lys22 } 27^{5.39}\end{array}$ & $\begin{array}{l}\text { Val281 }^{6.55} \\
\text { Trp284 }^{6.58} \\
\text { Leu300 }^{7.35} \\
\text { Ile304 }\end{array}$ & $\begin{array}{l}\text { Leu125 } 5^{3.29} \\
\text { Tyr129 } \\
\text { Leu200 } 200^{\text {ECL2 }} \\
\text { Phe202 } \\
\text { Ser206 } \\
\text { Asp21 } 210^{5.35}\end{array}$ \\
\hline
\end{tabular}

a The residues in Bold had key contributions to the pyridyl ring of NAP, NMP, and NGP binding.

matic pyridyl ring of NMP and residue Trp318 7.35 . In all, NMP showed high binding affinity to site A of the MOR after MD simulations.

In the MOR-NGP complex, the glycine linker increased the space between morphinan skeleton and the pyridyl ring of NGP, which made it difficult to accommodate the pyridyl ring of NGP in site A of the MOR. Conversely, site B of the MOR had a hydrophobic pocket including residues Leu2 $219^{\mathrm{ECL} 2}$ and Phe $221^{\mathrm{ECL} 2}$, which could form favorable hydrophobic interactions with the aromatic pyridyl ring of NGP. Hence, the pyridyl ring of NGP seemed to prefer site B of the MOR. Meanwhile, the amide linker was also an electron withdrawing group to the pyridyl ring of NGP, which made the electrostatic interaction between the pyridyl ring and the residue Glu2295.35 in MOR-NGP complex almost equal to that in MORNAP complex. As the glycine group would increase the length of the space between morphinan skeleton and pyridyl ring of NGP, which could result in the pyridyl ring of NGP moving close to residues Leu219 $19^{\mathrm{ECL} 2}$ and Phe $221^{\mathrm{ECL} 2}$ but moving away from residue Thr218 ${ }^{\mathrm{ECL} 2}$ (Table 4). In consequence, the hydrophobic interactions between the pyridyl ring of NGP and residues Leu2 $19^{\mathrm{ECL} 2}$ and
Phe $221^{\mathrm{ECL} 2}$ would be stronger than that in the MOR-NAP complex. However, the hydrogen bonding between the nitrogen atom of the pyridyl ring and residue Thr218 $18^{\mathrm{ECL} 2}$ in MOR-NAP complex was weakened in the MOR-NGP complex. Overall, NGP preferred to site $B$ of the MOR after MD simulations.

\subsection{Analysis of NMP and NGP in the 'address' domain of the KOR after MD simulations}

Similar binding sites of the pyridyl ring of NMP in the MOR were also observed in the KOR (Fig. 6). In the KOR-NMP complex, though the nitrogen atom of the pyridyl ring of NMP had a relatively stronger ability to keep a proton and a negatively charged residue Glu297 $7^{6.58}$ located at site A of KOR, the electrostatic interaction between the pyridyl ring of NMP and residue Glu297 2.58 was not obvious within site A of the KOR due to the distance in between. On the other hand, hydrophobic residues Ile290 ${ }^{6.51}$, Phe293 ${ }^{6.54}$, and Ile $294^{6.55}$ at site A of the KOR might form somehow weak hydrophobic interactions with the pyridyl ring of NMP to accom- 
Table 4

The measured distances between atoms on critical amino acid residues and atoms on the ligands from NMP-MOR, NMP-KOR, NMP-DOR, NGP-MOR, NGP-KOR, and NGPDOR complexes.

\begin{tabular}{|c|c|c|c|}
\hline $\begin{array}{l}\text { Binding site of the 'address' } \\
\text { moiety }\end{array}$ & Atom of residue & $\begin{array}{l}\text { Atom of } \\
\text { ligand }\end{array}$ & $\begin{array}{l}\text { Shortest } \\
\text { distance }(\AA)\end{array}$ \\
\hline NMP and NAP in MOR ${ }^{\text {site } A}$ & $\begin{array}{l}\text { NZ@Lys233 } \\
\text { NZ.39 } \\
\text { CG1@ } 233^{5.39} \\
\text { CG2@Val300 } 300^{6.55} \\
\text { NZ@Lys303 } \\
\text { NZ@Lys } 303^{6.58} \\
\text { CZ2@Trp318 } \\
\text { CZ2@Trp318 }\end{array}$ & $\begin{array}{l}\text { N56@NAP } \\
\text { N56@NMP } \\
\text { C57@NAP } \\
\text { C52@NMP } \\
\text { N56@NAP } \\
\text { N56@NMP } \\
\text { C55@NAP } \\
\text { C54@NMP }\end{array}$ & $\begin{array}{l}4.17 \\
5.63 \\
3.94 \\
5.69 \\
7.74 \\
7.30 \\
6.00 \\
4.44\end{array}$ \\
\hline NGP and NAP in MOR ${ }^{\text {site } B}$ & $\begin{array}{l}\text { OG1@Thr218 } \\
\text { OG1@Thr218 } \\
\text { CBCLeu219 } 19^{\mathrm{ECL} 2} \\
\text { CB@Leu219 } \\
\text { CE2@Phe221 } 21^{\mathrm{ECL} 2} \\
\text { CE2@Phe221 } \\
\text { OE2@ Glu229 } \\
\text { OE2.35 }\end{array}$ & $\begin{array}{l}\text { N56@NAP } \\
\text { N56@NGP } \\
\text { C57@NAP } \\
\text { C57@NGP } \\
\text { C57@NAP } \\
\text { C55@NGP } \\
\text { C58@NAP } \\
\text { C54@NGP }\end{array}$ & $\begin{array}{l}3.61 \\
5.64 \\
4.20 \\
4.38 \\
5.51 \\
4.82 \\
4.59 \\
5.22\end{array}$ \\
\hline NMP in $\mathrm{KOR}^{\text {Site } \mathrm{A}}$ & $\begin{array}{l}\text { CD@Ile290 } \\
\text { CD2.51 } \\
\text { CG1@Ile294 } 293^{6.55} \\
\text { OE1@Glu297 } \\
\text { CD2@Tyr312 }\end{array}$ & $\begin{array}{l}\text { C54@NMP } \\
\text { C12@NMP } \\
\text { C57@NMP } \\
\text { N56@NMP } \\
\text { C54@NMP }\end{array}$ & $\begin{array}{l}4.77 \\
5.36 \\
5.70 \\
5.58 \\
5.59\end{array}$ \\
\hline NGP in $\mathrm{KOR}^{\text {Site } \mathrm{B}}$ & $\begin{array}{l}\text { CB@Leu212 } 22^{\mathrm{ECL} 2} \\
\text { CE2@Phe214 } \\
\text { OD2L2@Asp223 }\end{array}$ & $\begin{array}{l}\text { C54@NGP } \\
\text { C57@NGP } \\
\text { N56@NGP }\end{array}$ & $\begin{array}{l}4.72 \\
5.31 \\
5.21\end{array}$ \\
\hline NMP in $\mathrm{DOR}^{\text {Site B }}$ & $\begin{array}{l}\text { CD2@Leu200 } \\
\text { CE1@Phe202 } \\
\text { OD1@Asp210 }\end{array}$ & $\begin{array}{l}\text { C57@NMP } \\
\text { C57@NMP } \\
\text { C54@NMP }\end{array}$ & $\begin{array}{l}4.18 \\
7.68 \\
6.10\end{array}$ \\
\hline NGP in $\mathrm{DOR}^{\text {Site } \mathrm{A}}$ & $\begin{array}{l}\text { CH2@Trp } 284^{6.58} \\
\text { CG@Leu300 }\end{array}$ & $\begin{array}{l}\text { C55@NGP } \\
\text { C58@NGP }\end{array}$ & $\begin{array}{l}4.20 \\
4.95\end{array}$ \\
\hline
\end{tabular}

modate the ligand. Thus, comparing to its high binding affinity in the MOR, NMP showed much lower affinity to the KOR.

The binding mode of NGP in the KOR was also similar to that in the MOR. Comparing Fig. 6(b) with Fig. 5(b), it could be found that residues Leu212 ${ }^{\mathrm{ECL} 2}$, Phe214 ${ }^{\mathrm{ECL} 2}$, and Asp $223^{5.35}$ in the KOR were at the conserved position of residues Leu2 $19^{\mathrm{ECL} 2}$, Phe $221^{\mathrm{ECL} 2}$, and Glu2295.35 in the MOR. On the other hand, the electrostatic interaction between the pyridyl ring in NGP and residue Asp223 $3^{5.35}$ was also an unfavorable distance due to the stretched conformation of the ligand. In addition, the hydrophobic interactions between the pyridyl ring in NGP and residues Leu212 $2^{\mathrm{ECL} 2}$ and Phe214 ${ }^{\mathrm{ECL} 2}$ in the KOR-NGP complex seemed weaker than those in the MORNGP complex as reflected by the ligand-residue distance in Table 4. Therefore, NGP also showed reasonable selectivity to the MOR over the KOR.

\subsection{Analysis of NMP and NGP in the 'address' domain of the DOR after MD simulations}

From Table 2 and Figs. 5-7, it was obviously that residues $\operatorname{Trp} 318^{7.35}$, Tyr312 $2^{7.35}$, and Leu300 $0^{7.35}$ were at a conserved position of site A of the MOR, KOR, and DOR, respectively. As the bulkiness and electronic properties of the side chain of Leu300 $0^{7.35}$ (DOR) was very different from those of $\operatorname{Trp} 318^{7.35}$ (MOR) and Tyr312 3.35 (KOR), the conformation of site A of the DOR could be different from those of the MOR and KOR. For example, the space of site A of the DOR was larger than those of the MOR and KOR (Figs. 57). Thus, the binding sites of the pyridyl ring of NMP and NGP in the DOR would be different from those in the MOR and KOR.

In DOR-NMP complex, the steric effect caused by the methyl group on the pyridyl ring of NMP would make the pyridyl ring of NMP moving away from Phe $202^{\mathrm{ECL} 2}$ and Asp210 5.35 and closer to
Leu200 ${ }^{\mathrm{ECL} 2}$ in the site B of the DOR (Table 4). Consequently, only some hydrophobic interaction (e.g. the pyridyl ring of NMP and residue Leu $200^{\mathrm{ECL} 2}$ ) existed between the pyridyl ring of NMP and the site B of the DOR. Thus, comparing to the binding affinities of NMP in the MOR and KOR, the binding affinity of NMP to the DOR was the lowest.

As described above, the space of site A of DOR was large enough to accommodate the pyridyl ring of NGP. At site A of the DOR, residues $\operatorname{Trp} 284^{6.58}$ and Leu300 7.35 could form relatively weak hydrophobic interactions with the pyridyl ring of NGP (Table 4). In result, NGP showed lower affinity to the DOR compared to that in the MOR.

\section{Conclusion}

NAP derivatives, NMP and NGP, had shown a promising selectivity profile at three opioid receptors. These two compounds have been designed and synthesized based on 'message-address' concept where the 'address' moiety of NMP and NGP was assumed to determine selectivity. Docking studies of NMP and NGP on each of three opioid receptors suggested presence of two distinct 'address' domains in the receptors, each capable to interact with the 'address' moieties of NMP and NGP. Furthermore, the results of the molecular dynamics simulations on NMP and NGP in three opioid receptors showed that the binding of the pyridyl ring of NMP and NGP with at least one of the two 'address' domains of the receptors were generally stable.

In the MOR the two 'address' domains had distinct chemical characteristics that site A had a positively charged residue while site $B$ had a negatively charged residue. Hence, the capability of the nitrogen atom on the pyridyl ring of NMP and NGP to keep a proton would affect the binding modes of NMP and MGP. Moreover, the steric effect caused by the methyl group on the pyridyl ring of NMP and the increment of the spacer length between 'message' and 'address' moieties caused by the glycine group on the pyridyl ring of NGP also had impacts on their binding to the MOR. This could be further evidenced by binding of NMP and NGP with the KOR and DOR. Therefore, these results provided the detailed information on receptor-ligand interactions and presented a strategy to modulate selectivity of NAP derivatives among the opioid receptors. Upon our future molecular design to achieve higher selectivity to the MOR over the DOR and KOR, the more favored binding mode of each lead compound should be first considered over the less favored one. In those favored binding pockets, unique chemical features of the side chains from the specific amino acid residues interacting with the lead will be applied to design the new substitutions of the 6-position 'address' portion of the next generation ligands.

In conclusion, these studies provided as an example where molecular modeling techniques, including molecular docking and dynamics simulations, along with structure activity relationship analyses can help explore receptor binding modes as well as guide future ligand design.

\section{Materials and methods}

\subsection{Preparing the structure of complexes}

The X-ray crystal structures for MOR $\left(4 \mathrm{DKL}^{8}\right)$, KOR $\left(4 \mathrm{DJH} \mathrm{H}^{9}\right)$ and DOR $\left(4 \mathrm{EJ} 4^{12}\right)$ were retrieved from PDB Data Bank at http://www. rcsb.org. Each opioid receptor model was built by adding hydrogen atoms, assigning Gasteiger-Hückel charges, and optimizing hydrogen coordinates by a 10,000 iteration minimization while holding all heavy atoms as fixed under the Tripos forcefield (TFF) in Sybyl-X 2.0. Small molecules were also sketched in Sybyl-X 2.0 
and their Gasteiger-Hückel charges were assigned before energy minimization $\left(10,000\right.$ iterations) under the TFF. ${ }^{49}$

\subsection{Docking studies}

GOLD 5.1, ${ }^{45}$ an automated genetic algorithm based docking program was employed to perform the docking studies with standard default settings, unless otherwise specified. The binding site was defined to include all atoms within $10 \AA$ of the $\gamma$-carbon atom of Asp $^{3.32}$ of the three opioid crystal structures. Distance constraints of $4 \AA$ A between the piperidine nitrogen of the ligands' morphinan nucleus and $\mathrm{Asp}^{3.32}$, and between the ligands' tetrahydrofuran oxygen and the phenolic oxygen of $\mathrm{Tyr}^{3.33}$ were included in the docking runs to reproduce ionic interaction between the acidic receptor residue and quaternary nitrogen of the ligand and hydrogen bond interaction between hydrogen bond donor tyrosine and hydrogen bond acceptor tetrahydrofuran oxygen of the 'morphinan' skeleton in the model. Based on the fitness scores and the binding orientation of each ligand within the binding cavity, the GOLD-docked solutions were selected and merged into the receptor. The interactions between ligand and receptor within the binding pocket were optimized; clashes and strain energy were removed by energy minimizing the receptor-ligand structure complexes (1000 iterations under TFF) in Sybyl-X 2.0. After that, HINT algorism was applied to analyze the hydropathic interactions between ligand and receptor. ${ }^{50}$

\subsection{Building the lipid membrane}

VMD 1.9.1 ${ }^{51}$ was applied to prepare lipid membrane embedded receptor-ligand ionized water box system for molecular dynamics (MD) simulations. The Coordinate (pdb) and connectivity files (psf) were generated for receptor-ligand complex using the psfgen module. The VMD membrane module was employed to create a lipid bilayer of POPC (1-Palmitoyl-2-oleoylphosphatidylcholine). Orientation of protein in membrane (OPM) $)^{52}$ server is used to orient the receptor within the lipid bilayer. This was followed by addition of 30 Å of water layers to both sides of membrane at the vertical axis, using Solvate plugin. All the waters and POPC molecules at a distance of $0.65 \AA$ or less from the receptor-ligand complex were then deleted followed by deletion of waters within the POPC membrane. The water system was then ionized to $0.15 \mathrm{M}$ of $\mathrm{NaCl}$ by the Autoionize plugin. The ligand parameter and topology files were obtained from Paramchem server. ${ }^{53}$

\subsection{Molecular dynamics simulation}

All molecular modeling simulations were performed using NAMD 2.8. ${ }^{54}$ All MD simulations were carried out in four stages. In the first stage, equilibration of the fluid-like lipid bi-layer was performed via minimization (1000 iterations) followed by NPT equilibration (pressure equilibration) of the lipid tails for a period of $0.5 \mathrm{~ns}$. Simulations were carried out using the CHARMM force field with CHARMM22 parameters for protein, CHARMM27 parameters for lipids and CMAP corrections for proline, glycine and alanine dipeptides ${ }^{55}$ with a time-step of 2 femtoseconds (fs). Periodic boundary conditions were employed, and Particle Mesh Ewald (PME) summation was used to calculate long-range electrostatic interactions. Non-bonded interactions were calculated with a smooth cutoff between 10 and $12 \AA$ with a frequency of $1 \mathrm{fs}$. Constant pressure and temperature at $310 \mathrm{~K}$ was maintained via Langevin dynamics. In the second stage, an NPT equilibration of the system was run for a period of $1 \mathrm{~ns}$ with harmonic constraints placed on protein, ligand and crystallographic water atoms (5 kcal/(mol- $\AA)$ ) while keeping all the parameters same as earlier. The harmonic restraint was released in stage 3 and the entire sys- tem was equilibrated using the NVT canonical ensemble for a further $1 \mathrm{~ns}$. The final production run was conducted using an NVT ensemble where the whole system was equilibrated for $10 \mathrm{~ns}$.

\section{Acknowledgements}

The work was partially supported by PHS Grant DA024022 (Y. Z.). The content in this work is solely the responsibility of the authors and does not necessarily represent the official views of the National Institute on Drug Abuse or the National Institutes of Health.

\section{References}

1. Fredriksson R, Lagerström MC, Lundin L-G, Schiöth HB. The G-protein-coupled receptors in the human genome form five main families. Phylogenetic analysis, paralogon groups, and fingerprints. Mol Pharmacol. 2003;63:1256-1272.

2. Overington JP, Al-Lazikani B, Hopkins AL. How many drug targets are there? Nat Rev Drug Discovery. 2006;5:993-996.

3. Tyndall JD, Sandilya R. GPCR agonists and antagonists in the clinic. Med Chem. 2005; 1:405-421.

4. Katritch V, Cherezov V, Stevens RC. Structure-function of the G-protein-coupled receptor superfamily. Annu Rev Pharmacool Toxicol. 2013;53:531.

5. Harrison LM, Kastin AJ, Zadina JE. Opiate tolerance and dependence: receptors, G-proteins, and antiopiates. Peptides. 1998;19:1603-1630.

6. Kieffer BL. Opioids: first lessons from knockout mice. Trends Pharmacol Sci. 1999;20:19-26.

7. Clark JA, Liu L, Price M, Hersh B, Edelson M, Pasternak GW. Kappa opiate receptor multiplicity: evidence for two U50, 488-sensitive kappa 1 subtypes and a novel kappa 3 subtype. J Pharmacol Exp Ther. 1989;251:461-468.

8. Manglik A, Kruse AC, Kobilka TS, et al. Crystal structure of the [micro]-opioid receptor bound to a morphinan antagonist. Nature. 2012;485:321-326.

9. Wu H, Wacker D, Mileni M, et al. Structure of the human kappa-opioid receptor in complex with JDTic. Nature. 2012;485.

10. Fenalti G, Giguere PM, Katritch V, et al. Molecular control of [dgr]-opioid receptor signalling. Nature. 2014;506:191-196.

11. Thompson AA, Liu W, Chun E, et al. Structure of the nociceptin/orphanin FQ receptor in complex with a peptide mimetic. Nature. 2012;485:395-399.

12. Granier S, Manglik A, Kruse AC, et al. Structure of the $\delta$-opioid receptor bound to naltrindole. Nature. 2012;485:400-404.

13. Huang W, Manglik A, Venkatakrishnan A, et al. Structural insights into [micro]opioid receptor activation. Nature. 2015;524:315-321.

14. Fenalti G, Zatsepin NA, Betti C, et al. Structural basis for bifunctional peptide recognition at human $\delta$-opioid receptor. Nat Struct Mol Biol. 2015;22:265-268.

15. Mcnicol E, Horowicz-Mehler N, Fisk RA, et al. Management of opioid side effects in cancer-related and chronic noncancer pain: a systematic review. J Pain. 2003;4:231-256.

16. Zimmerman DM, Leander JD. Selective opioid receptor agonists and antagonists: research tools and potential therapeutic agents. J Med Chem. 1990;33:895-902.

17. Schmidhammer H. 3 opioid receptor antagonists'. Prog Med Chem. 1998;35:83-132.

18. Fiellin DA, Kleber H, Trumble-Hejduk JG, Mclellan AT, Kosten TR. Consensus statement on office-based treatment of opioid dependence using buprenorphine. J Subst Abuse Treat. 2004;27:153-159.

19. Tejedor-Real P, Mico JA, Smadja C, Maldonado R, Roques BP, Gibert-Rahola J. Involvement of $\delta$-opioid receptors in the effects induced by endogenous enkephalins on learned helplessness model. Eur J Pharmacol. 1998;354:1-7.

20. Baamonde A, Daugé V, Ruiz-Gayo M, et al. Antidepressant-type effects of endogenous enkephalins protected by systemic RB 101 are mediated by opioid $\delta$ and dopamine D1 receptor stimulation. Eur J Pharmacol. 1992;216:157-166

21. Carlezon WA, Béguin C, Dinieri JA, et al. Depressive-like effects of the $\kappa$-opioid receptor agonist salvinorin $\mathrm{A}$ on behavior and neurochemistry in rats. $J$ Pharmacol Exp Ther. 2006;316:440-447.

22. Lalanne L, Ayranci G, Kieffer BL, Lutz P-E. The kappa opioid receptor: from addiction to depression, and back. Front Psychiatry. 2014;5:170.

23. Vant Veer A, Carlezon Jr WA. Role of kappa-opioid receptors in stress and anxiety-related behavior. Psychopharmacology. 2013;229:435-452.

24. Davis MP, Pasternak GW. Opioid receptors and opioid pharmacodynamics. Opioids Cancer Pain. 2005;2.

25. Eguchi M. Recent advances in selective opioid receptor agonists and antagonists. Med Res Rev. 2004;24:182-212.

26. Matthes HW, Maldonado R, Simonin F, et al. Loss of morphine-induced analgesia, reward effect and withdrawal symptoms in mice lacking the $\mu$ opioid-receptor gene. 1996.

27. Gaveriaux-Ruff C, Kieffer B. Opioid receptor genes inactivated in mice: the highlights. Neuropeptides. 2002;36:62-71.

28. Skoubis P, Matthes H, Walwyn W, Kieffer B, Maidment N. Naloxone fails to produce conditioned place aversion in $\mu$-opioid receptor knock-out mice. Neuroscience. 2001;106:757-763.

29. Soyka M, Roesner S. New pharmacological approaches for the treatment of alcoholism. Expert Opin Pharmacother. 2006;7:2341-2353. 
30. Ågmo A, Galvan A, Heredia A, Morales M. Naloxone blocks the antianxiety but not the motor effects of benzodiazepines and pentobarbital: experimental studies and literature review. Psychopharmacology. 1995;120:186-194.

31. Anton RF. Naltrexone for the management of alcohol dependence. N Engl J Med. 2008:359:715-721.

32. Keating GM. Nalmefene: a review of its use in the treatment of alcohol dependence. CNS Drugs. 2013;27:761-772.

33. Van Dorp EL, Yassen A, Dahan A. Naloxone treatment in opioid addiction: the risks and benefits. Expert Opin Drug Saf. 2007;6:125-132.

34. Miotto K, Mccann M, Basch J, Rawson R, Ling W. Naltrexone and dysphoria: fact or myth? Am J Addict. 2002;11:151-160.

35. Ritter AJ. Naltrexone in the treatment of heroin dependence: relationship with depression and risk of overdose. Aust N Z J Psychiatry. 2002;36:224-228.

36. Oslin DW, Berrettini WH, O'brien CP. Review: targeting treatments for alcohol dependence: the pharmacogenetics of naltrexone. Addict Biol. 2006;11:397-403.

37. Li G, Aschenbach LC, Chen J, et al. Design, synthesis, and biological evaluation of 6alpha- and 6beta-N-heterocyclic substituted naltrexamine derivatives as mu opioid receptor selective antagonists. J Med Chem. 2009;52:1416-1427.

38. Zaidi SA, Arnatt CK, He H, et al. Binding mode characterization of $6 \alpha$-and $6 \beta-\mathrm{N}-$ heterocyclic substituted naltrexamine derivatives via docking in opioid receptor crystal structures and site-directed mutagenesis studies: Application of the 'message-address' concept in development of mu opioid receptor selective antagonists. Bioorg Med Chem. 2013;21:6405-6413.

39. Yuan Y, Elbegdorj O, Chen J, et al. Structure selectivity relationship studies of

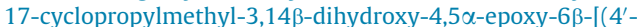
pyridyl)carboxamido]morphinan derivatives toward the development of the mu opioid receptor antagonists. Bioorg Med Chem Lett. 2011;21:5625-5629.

40. Perrin DD, Dempsey B, Serjeant EP. pKa Prediction for Organic Acids and Bases. Springer; 1981.

41. Albert A, Serjeant EP. Ionization Constants of Acids and Bases: A Laboratory Manual. Methuen; 1962.

42. Seki T, Minami M, Kimura C, Uehara T, Nakagawa T, Satoh M. Bremazocine recognizes the difference in four amino acid residues to discriminate between a nociceptin/orphanin FQ receptor and opioid receptors. The Japanese Journal of Pharmacology. 1998;77:301-306.
43. Ulens C, Baker L, Ratka A, Waumans D, Tytgat J. Morphine-6 $\beta$-glucuronide and morphine-3-glucuronide, opioid receptor agonists with different potencies. Biochem Pharmacol. 2001;62:1273-1282.

44. Xu H, Lu Y-F, Partilla JS, et al. Opioid peptide receptor studies, 11: involvement of Tyr148, Trp318, and His319 of the rat-opioid receptor in binding of -selective ligands. Synapse (New York). 1999;32:23-28.

45. Jones G, Willett P, Glen RC, Leach AR, Taylor R. Development and validation of a genetic algorithm for flexible docking. J Mol Biol. 1997;267:727-748.

46. Gohlke H, Kiel C, Case DA. Insights into protein-protein binding by binding free energy calculation and free energy decomposition for the Ras-Raf and RasRalGDS complexes. J Mol Biol. 2003;330:891-913.

47. Hou T, Mclaughlin W, Lu B, Chen K, Wang W. Prediction of binding affinities between the human amphiphysin-1 SH3 domain and its peptide ligands using homology modeling, molecular dynamics and molecular field analysis. $J$ Proteome Res. 2006;5:32-43.

48. Wang J, Hou T, Xu X. Recent advances in free energy calculations with a combination of molecular mechanics and continuum models. Curr Comput Aided Drug Des. 2006;2:287-306.

49. Ballesteros JA, Weinstein $\mathrm{H}$. Integrated methods for the construction of threedimensional models and computational probing of structure-function relations in G protein-coupled receptors. 1995; 25 : 366-428

50. Kellogg GE, Abraham DJ. Hydrophobicity: is LogP o/w more than the sum of its parts? Eur J Med Chem. 2000;35:651-661.

51. Humphrey W, Dalke A, Schulten K. VMD: visual molecular dynamics. J Mol Graph. 1996;14:33-38.

52. Lomize MA, Lomize AL, Pogozheva ID, Mosberg HI. OPM: orientations of proteins in membranes database. Bioinformatics. 2006;22:623-625.

53. Vanommeslaeghe K, Hatcher E, Acharya C, et al. CHARMM general force field: a force field for drug-like molecules compatible with the CHARMM all-atom additive biological force fields. J Comput Chem. 2010;31:671-690.

54. Phillips JC, Braun R, Wang W, et al. Scalable molecular dynamics with NAMD. J Comput Chem. 2005;26:1781-1802.

55. Best RB, Zhu X, Shim J, et al. Optimization of the additive CHARMM all-atom protein force field targeting improved sampling of the backbone $\phi, \psi$ and sidechain $\chi 1$ and $\chi 2$ dihedral angles. J Chem Theory Comput. 2012;8:3257-3273. 